\title{
Study on the Pyridoxal Kinase of Mouse Brain ${ }^{1}$
}

\author{
Michiko Tsubosaka and Katashi Makino ${ }^{2}$ \\ Department of Biochemistry, The Jikei University School \\ of Medicine Tokyo. (Post No. 105)
}

(Received July 30, 1968)

The properties of the pyridoxal kinase of mouse brain were studied and the following results were obtained.

1. It was concluded that toxopyrimidine seemed to be phosphorylated by the same phosphokinase as pyridoxal based on the following reasons: the mutual competitive inhibition, the coincidence of the metal requirements, the denaturation effects of heat treatment on the enzyme and the behaviors of inhibitors for both substrates.

2. The substrate specificities of the pyridoxal-kinase were investigated and the following results were obtained: (a) The pyridoxal-kinase was able to act on both certain pyridine and pyrimidine derivatives (b) The 2-methyl of the pyrimidine ring was able to be substituted with $\mathrm{C}_{2} \mathrm{H}_{5}$ or $\mathrm{SCH}_{3}$ group for $\mathrm{CH}_{3}$ group (c) The 4 position of the pyridine ring was able to be substituted with $\mathrm{CH}_{2} \mathrm{OH}, \mathrm{CH}_{2} \mathrm{NH}_{2}$ or $\mathrm{CH}_{3}$ group for $\mathrm{CHO}$ group (d) The compounds without a hydroxymethyl group in the 5 position of the pyridine ring were not phosphorylated at all (such as pyrithioxine) or slightly phosphorylated in such a special case as 5-deoxypyridoxine

In the early experiment, the authors (1) studied on the inhibitory action of TXP on the PAL-kinase of mouse brain. It was found that TXP not only inhibited the PAL-kinase, but also was phosphorylated by the enzyme to TXP-P. It is an interesting fact that PAL (one of pyridine compounds) and TXP (one of pyrimidine compounds) are phosphorylated by the same phosphokinase. In this paper, the authors tried to investigate the properties of the purified PAL-kinase of mouse brain, particularly the substrate specificities ${ }^{3}$.

1 Abbreviations used: TXP, toxopyrimidine (2-methyl-4-amino-5-hydroxymethylpyrimidiene), Merck Index, 7th edition, Merck and Co. (1960) p. 1055, PAL, pyridoxal; TXP-P, toxopyrimidine phosphate (5); GSH, reduced glutathione; TCA, trichloroacetic acid; PCA, perchloric acid; PIN, pyridoxine; PAM, pyridoxamine.

2 壼阪美智子, 牧野 堅.

${ }^{3}$ Concerning the pyridoxal kinase of rat and beef brain there is a brief description of Snell et al (7). 


\section{Experimental Procedures}

\section{Preparation of the PAL-kinase}

All operations except those specified were conducted at 0 to $4^{\circ} .35 \mathrm{~g}$ of mouse brain were homogenized with a ten fold excess of cold distilled water. The brain homogenate was centrifuged at $20,000 \times g$ for 30 minutes and the precipitate was discarded. To the supernatant solution were added $10 \mathrm{ml}$ of $0.5 \mathrm{M}$ phosphate buffer, $\mathrm{pH} 7.2$, and successively $5 \mathrm{ml}$ of $1 M$ solution of calcium acetate carefully with continuous stirring by a magnetic stirrer. After stirring for five minutes, the Ca-acetate gel formed was removed by centrifugation at $20,000 \times g$ for 20 minutes, and the supernatant was salted out with ammonium sulfate. The protein fraction insoluble between 35 and $60 \%$ saturation was separated and dissolved in a small volume of $0.005 M \mathrm{~K}$-phosphate buffer, $\mathrm{pH} 6.8$, containing $0.1 \mathrm{~m} M \mathrm{GSH}$ and dialyzed against the same buffer overnight. After the precipitate formed was removed by centrifugation, the remaining solution was poured over a column containing a 500 to 600 fold excess of hydroxylapatite gel to protein. Hydroxylapatite gel was prepared by the method of Tiselius (2). After the column was washed with $50 \mathrm{ml}$ of $0.02 M \mathrm{~K}$-phosphate buffer, $\mathrm{pH} 6.8$, the PAL-kinase was eluted with $200 \mathrm{ml}$ of $0.075 M$ K-phosphate buffer, $\mathrm{pH}$ 6.8. Fractions containing kinase activity were pooled and the protein fraction insoluble between 35 and $55 \%$ saturation with ammonium sulfate was dialyzed overnight as described above. After the precipitated material was removed by centrifugation, the clarified solution, after adjusted to $0.005 M$ as to phosphate content, was poured over a column containing a 100 -fold excess (cellulose to protein) of DEAE-cellulose. DEAE-cellulose (Brown Company) was recycled through acid and base before use.

The protein adsorbed on the column and washed with $0.005 M$ phosphate buffer, was eluted fractionally in a linear gradient established between 0.025 and $0.5 \mathrm{M}$ K-phosphate buffers, $\mathrm{pH}$ 6.8. When the mixing chamber was filled with $100 \mathrm{ml}$ of $0.025 M \mathrm{~K}$-phosphate buffer, $\mathrm{pH} 6.8$, the kinase activity appeared in the 30 to $95-\mathrm{ml}$ fractions of the effluent. The kinase activity was determined on the abovementioned whole fractions which were fractionated $4 \mathrm{ml}$ apiece. The 42 to $72-\mathrm{ml}$ fractions showing equal specific activity were pooled, and ammonium sulfate was added to $60 \%$ saturation. The active protein was collected by centrifugation and dialyzed as mentioned above.

The purified PAL-kinase preparation thus obtained was 60 to $70 \%$ pure ultracentrifugically and did not contain ATPase activity. The specific activity of this enzyme was increased 3550 times the orginal homogenate as indicated in Table 1.

TABLE 1

Purification of Pyridoxal Kinase of Mouse Brain

\begin{tabular}{lcc}
\hline \multicolumn{1}{c}{ Fraction } & Specific activity & Relative purity \\
\hline 1. Homogenate & 0.474 & 1 \\
2. Centrifuged extract & 2.92 & 6.2 \\
3. Ca-phosphate gel fractionation & 10.1 & 21.4 \\
4. (NH $)_{2} \mathrm{SO}_{4} \quad 35$ to $60 \%$ saturation & 124.5 & 265 \\
5. Hydroxylapatite gel & 610 & 1,285 \\
6. (NH $)_{2}$ SO $_{4}$ 34 to 55\% saturation & 1,150 & 2,420 \\
7. DEAE-cellulose & 1,680 & 3,550 \\
\hline
\end{tabular}




\section{Determination of the PAL-kinase Activity}

The assay conditions were given in the respective figures and tables. When PAL was used as the substrate of the kinase, the reaction was stopped by the addition of $0.2 \mathrm{ml}$ of $50 \% \mathrm{TCA}$ and was refrigerated to $0^{\circ}$, and $0.2 \mathrm{ml}$ of $50 \%$ $\mathrm{H}_{2} \mathrm{SO}_{4}$ and $0.2 \mathrm{ml}$ of the phenylhydrazine reagent $(200 \mathrm{mg}$ of phenylhydrazine $\cdot \mathrm{HCl}$ dissolved in $10 \mathrm{ml}$ of $10 \mathrm{~N} \mathrm{H}_{2} \mathrm{SO}_{4}$ ) were added. After 30 minutes the optical density at $410 \mathrm{~m} \mu$ was measured (Wada and Snell (3)).

When TXP was used as the substrate of PAL-kinase, the reaction was stopped by the addition of $0.5 \mathrm{ml}$ of $4.5 \mathrm{~N} \mathrm{PCA}$, and $4.5 \mathrm{~N} \mathrm{KOH}$ was added for neutralization. The potassium salt precipitated was removed by centrifugation and the supernatant solution was poured on a column $(0.8 \times 4.0 \mathrm{~cm}$ ) of Dowex $1 \times 4$ (formate form). After $25 \mathrm{ml}$ of distilled water containing TXP ran out, TXP-P was eluted by $0.1 \mathrm{~N} \mathrm{HCOOH}$. As in this fraction a small amount of AMP, contaminated in the sample of ATP, was eluted together with TXP-P, the control without TXP and PAL-kinase was also made. The effluent was pooled $5 \mathrm{ml}$ apiece and the optical density at $245 \mathrm{~m} \mu$ was read with spectrophotometer.

When other compounds were used as the substrate of PAL-kinase, ADP formed was determined by the method of Potter et al. (4) The reaction was stopped by the addition of $0.5 \mathrm{ml}$ of $4.5 \mathrm{~N} \mathrm{PCA}$, and $4.5 \mathrm{~N} \mathrm{KOH}$ was added for neutralization as described above. The salt formed was discarded, $0.9 \mathrm{ml}$ of $1 \mathrm{M} \mathrm{NH}_{4} \mathrm{OH}$ was added to the remaining solution, and the solution was poured over a column containing Dowex $1 \times 4$ (Cl-form) $(0.8 \times 4.0 \mathrm{~cm})$. After $25 \mathrm{ml}$ of distilled water and $170 \mathrm{ml}$ of $0.003 \mathrm{~N} \mathrm{HCl}$ ran out, ADP was eluted by $45 \mathrm{ml}$ of $0.02 \mathrm{M} \mathrm{NaCl}-0.01 \mathrm{~N}$ $\mathrm{HCl}$ solution. The effluent was fractionated in four parts $(a) 15,(b) 10,(c) 10$ and (d) $10 \mathrm{ml}$, respectively. ADP content was calculated from the optical density of fractions $(b)$ to $(d)$ at $260 \mathrm{~m} \mu$.

Specific activity of the kinase was expressed as units per mg of protein, where 1 unit was the amount of protein that formed $1 \mathrm{~m} \mu$ mole of PAL-P in 1 hour at $38^{\circ}$.

\section{Other Methods}

On paper chromatography, $B_{6}$ derivatives were detected by their ultraviolet absorption, their fluorescence or the coloration by Gibbs' reagent. TXP derivatives were detected by their ultraviolet absorption on paper chromatography. The quantitative analysis of phosphoric acid was carried out by the method of Allen (5). Protein content was determined by the optical density at $280 \mathrm{~m} \mu$.

\section{Results AND Discussion}

\section{Phosphorylation of TXP and PAL and the Mutual Competition}

TXP was phosphorylated by the purified PAL-kinase to TXP-P as well as PAL (Figs. 1 and 2). The Michaelis constants were $0.86 \times 10^{-4} M$ for PAL and $2.67 \times 10^{-4} M$ for TXP. When the two substrates were incubated in the respective best condition with the kinase in the presence of ATP, TXP was phosphorylated with the rate no less than 2-fold for PAL. Therefore, PAL and TXP served as competitive substrates for this enzyme (Figs. 3 and 4). As an inhibitor for the PAL-kinase PAL was much more potent than TXP, that is, for the phosphorylation of PAL by the kinase, TXP inhibited, at an equal concentration to PAL, the phosphorylation of PAL 


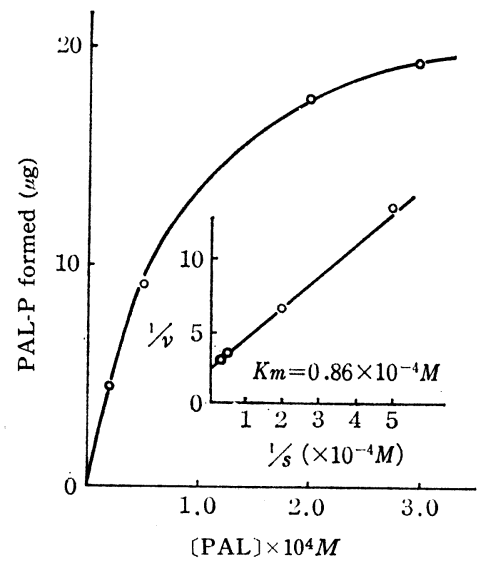

FIG. 1 Phosphorylation of Pyridoxal by the Pyridoxal Kinase of Mouse Brain

$v$, PAL-P formed per minute $(\mu \mathrm{g})$. Incubation mixture contained $0.15 \mathrm{~m} M$ ATP, $0.01 \mathrm{~m} M$ $\mathrm{ZnSO}_{4}, 50 \mathrm{mM}$ K-phosphate buffer, pH 5.52, $75 \mu \mathrm{g}$ purified kinase and PAL. Total volume $2.5 \mathrm{ml}$. Incubation was perfomed at $38^{\circ}$ for 1 hour.

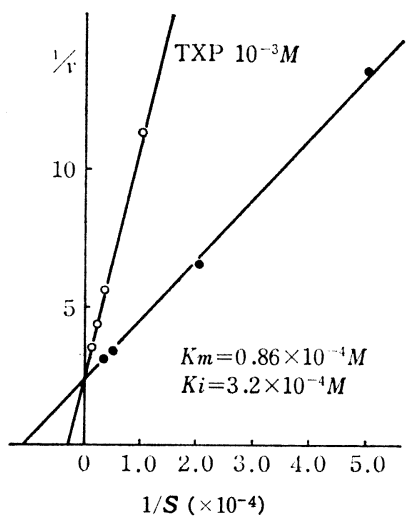

FIG. 3 Competitive Inhibition of Toxopyrimidine for the Phosphorylation of Pyridoxal

$v$, PAL-P formed per minute $(\mu \mathrm{g})$. Incubation mixture contained $0.15 \mathrm{~m} M$ ATP, $0.01 \mathrm{~m} M$ $\mathrm{ZnSO}_{4}, 50 \mathrm{~m} M$ K-phosphate buffer, pH 5.52, $75 \mu \mathrm{g}$ kinase and PAL. Total volume $2.5 \mathrm{ml}$. Incubation was carried out at $38^{\circ}$ for 1 hour.

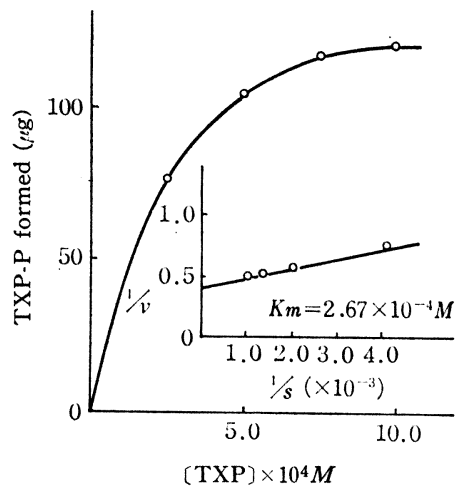

FIG. 2 Phosphorylattion of Toxopyrimidine by the Pyridoxal Kinase of Mouse Brain

$v$, TXP-P formed per minute $(\mu \mathrm{g})$. Incubation mixture contained $0.25 \mathrm{~m} M$ ATP, $0.01 \mathrm{~m} M$ $\mathrm{ZnSO}_{4}, 50 \mathrm{~m} M \mathrm{~K}$-phosphate buffer, $\mathrm{pH} 6.42$, $225 \mu \mathrm{g}$ purified kinase and TXP. Total volume $7.5 \mathrm{ml}$. Incubation was carried out at $38^{\circ}$ for 1 hour.

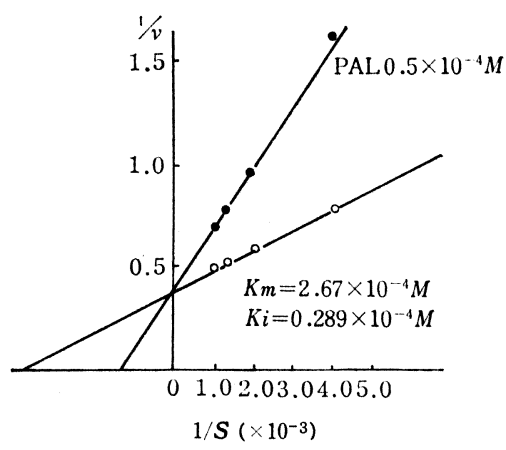

FIG. 4 Competitive Inhibition of Pyridoxal for the Phosphorylation of Toxopyrimidine $v$, TXP-P formed per minute $(\mu \mathrm{g})$. Incubation mixture contained $0.25 \mathrm{~m} M$ ATP, $0.01 \mathrm{~m} M$ $\mathrm{ZnSO}_{4}, 50 \mathrm{~m} M$ K-phosphate buffer, $\mathrm{pH} 6.42$, $225 \mu \mathrm{g}$ kinase and TXP. Total volume $7.5 \mathrm{ml}$. Incubation was carried out at $38^{\circ}$ for 1 hour. 


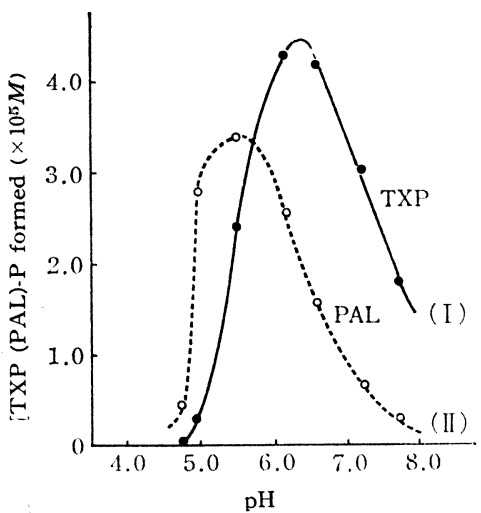

FIG. 5 pH Optima of Pyridoxal Kinase of Mouse Brain for the Phosphorylation of Pyridoxal and Toxopyrimidine

Incubation mixture in (I) contained 0.4 $\mathrm{m} M$ TXP and ATP, $0.01 \mathrm{~m} M \quad \mathrm{ZnSO}_{4}$, $50 \mathrm{~m} M \quad \mathrm{~K}$-phosphate buffer $1 \mathrm{pH} 4.9$ to $7.8)$ and $225 \mu \mathrm{g}$ kinase. Total volume 7.5 $\mathrm{ml}$. In (II), lncubation mixtures contained $0.3 \mathrm{~m} M$ PAL and ATP, $0.01 \mathrm{mM} \mathrm{ZnSO}$, $50 \mathrm{~m} M \quad \mathrm{~K}$-phosphate buffer $1 \mathrm{pH} 4.9$ to $7.8)$ and $75 \mu \mathrm{g}$ kinase. Total volume 2.5 ml. Incubation was carried out at $38^{\circ}$ for 1 hour. about $8 \%$ and $50 \%$ at $10^{-3} \mathrm{M} 20$-fold concentration to PAL. For the phosphorylation of TXP (at $0.25 \mathrm{~mm}$ ) by the kinase, PAL inhibited about $50 \%$ at $0.05 \mathrm{mM}$ and $80 \%$ at an equal concentration to TXP. The inhibitory constants $(\mathrm{Ki})$ were $3.2 \times 10^{-4} \mathrm{M}$ for TXP and $0.29 \times 10 M^{-4}$ for PAL.

\section{2. $p H$ Optimum}

The optimum $\mathrm{pH}$ of the kinase were approximately 5.5 forPAL and 6.4 for TXP (Fig. 5). At pH 5.0 PAL showed high affinity but TXP had rather low affinity for the kinase. On the other hand, TXP showed, at $\mathrm{pH} 6.4$, higher affinity for the enzyme than PAL. As the affinity of PAL and TXP for the kinase varied thus with $\mathrm{pH}$, the inhibition of TXP for phosphorylation of PAL by the kinase was expected to change with $\mathrm{pH}$. Therefore, the reaction mixtures containing $0.15 \mathrm{mM}$ PAL and 1.0 $m M$ TXP were incubated in the presence of the kinase and ATP at several $\mathrm{pH}$ levels. It was confirmed, as shown in Table 2 , that the inhibition of TXP markedly varied with $\mathrm{pH}$ as expected.

TABLE 2

pH-Dependence of the Inhibition of Pyridoxal Kinase of Mouse Brain by Toxopyrimidine

\begin{tabular}{cc}
\hline $\mathrm{pH}$ & Inhibition ratio \\
\hline & per cent \\
4.96 & 0 \\
5.52 & 25.6 \\
6.60 & 57.4 \\
7.25 & 37.3 \\
\hline
\end{tabular}

Incubation mixture contained $0.15 \mathrm{~m} M$ PAL and ATP, $1.0 \mathrm{~m} M$ TXP, $0.01 \mathrm{~m} M \mathrm{ZnSO}_{4}$, $50 \mathrm{~m} M \mathrm{~K}$-phosphate buffers of various $\mathrm{pH}$ levels and $75 \mu \mathrm{g}$ kinase. Total volume, 2.5 $\mathrm{ml}$. Incubation was carried out at $38^{\circ}$ for 1 hour.

\section{Identity of PAL-kinase and TXP-kinase}

It was concluded from the following experimental data that PAL and TXP were phosphorylated by the same enzyme.

Effects of metal ions - $\mathrm{Zn}^{2+}$ or $\mathrm{Co}^{2+}$ was essential either to the phosphorylation of TXP and to that of PAL (Fig. 6). The activation effect of $\mathrm{Co}^{2+}$ was approximately $80 \%$ of $\mathrm{Zn}^{2+}$. The optimal concentrations of $\mathrm{Co}^{2+}$ were approximately $1 \times 10^{-4}$ and $2 \times 10^{-4} M$ for PAL and TXP, respectively. $\mathrm{Mg}^{2+}$ was about $40 \%$ effective compared with $\mathrm{Zn}^{2+}$, and $\mathrm{Ca}^{2+}$ showed only a little effect. 


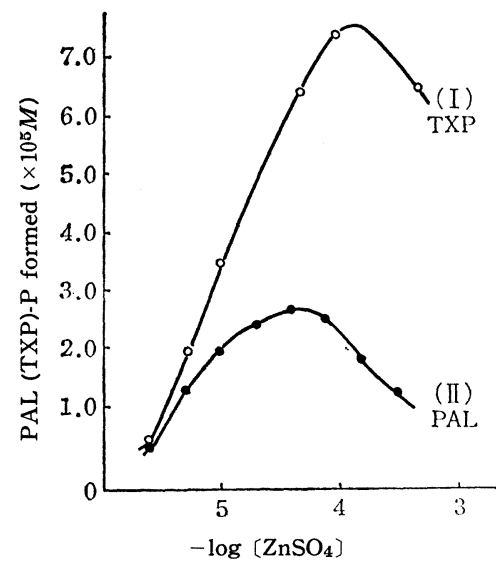

FIG. 6 Activation of Pyridoxal Kinase of Mouse Brain by $\mathrm{Zn}^{2+}$

Incubation mixture in (I) contained $0.5 \mathrm{~m} M$ TXP, $0.3 \mathrm{~m} M$ ATP, $50 \mathrm{~m} M \mathrm{~K}$-phosphate buffer, $\mathrm{pH} 6.42,225 \mu \mathrm{g}$ kinase and $\mathrm{ZnSO}_{4}$ of various concentrations. Total volume $7.5 \mathrm{ml}$. In (II), incubation mixture contained $0.3 \mathrm{~m} M$ PAL and ATP, $50 \mathrm{~m} M \mathrm{~K}$-phosphate buffer, $75 \mu \mathrm{g}$ kinase and $\mathrm{ZnSO}_{4}$ of various concentrations. Total volume 2.5 $\mathrm{ml}$. Incubation was performed at $38^{\circ}$ for 1 hour.

\section{Substrate Specificities}

For pyridoxine and pyridoxamine — It has been reported by Snell et al. (7) that PAL-kinase from several tissues of animals or bacteria phosphorylated not only PAL but also PIN and PAM. The PAL-kinase from mouse brain also phosphorylated PIN and PAM like PAL. The Michaelis constants were approximately $0.5 \times 10^{-4}$ and $2 \times 10^{-4} M$ for PIN and PAM, respectively (Figs. 7 and 8 ). The optimum

TABLE 3

Effects of Heat Treatment of the Pyridoxal Kinase on the Phosphorylation of Pyridoxal and Toxopyrimidine

\begin{tabular}{lcccc}
\hline \hline \multirow{2}{*}{ Substrates } & \multicolumn{4}{c}{ PAL-P or TXP-P formed $(\mu \mathrm{g})$} \\
\cline { 2 - 5 } & control & $45^{\circ} a$ & $50^{\circ} a$ & $55^{\circ} a$ \\
\hline PAL & 14.1 & 7.6 & 2.2 & 0 \\
Ratio, activity to control $(\%)$ & 100 & 53.8 & 15.5 & 0 \\
TXP & 119 & 70 & 15.6 & 0 \\
Ratio, activity to control $(\%)$ & 100 & 59.0 & 13.1 & 0
\end{tabular}

a Heat treatment was carried out for 5 minutes at $\mathrm{pH} 4.96$.

Incubation mixture in (I) contained $0.3 \mathrm{~m} M$ PAL and ATP, $0.05 \mathrm{~m}^{2} \mathrm{ZnSO}_{4}, 0.05 \mathrm{~m} M$ $\mathrm{K}$-phoshate buffer, $\mathrm{pH} 5.52$, and $75 \mu \mathrm{g}$ kinase. Total volume $2.5 \mathrm{ml}$. In (2), incubation mixture contained $0.5 \mathrm{~m} M$ TXP, $0.3 \mathrm{~m} M$ ATP, $0.1 \mathrm{~m} M \mathrm{ZnSO}_{4}, 50 \mathrm{~m} M$ K-phosphate buffer, $\mathrm{pH} 6.42$, and $225 \mu \mathrm{g}$ kinase. Total volume $7.5 \mathrm{ml}$. Incubation was performed at $38^{\circ}$ for 1 hour. 
TABLE 4

Inhibitory Effect of Certain Carbonyl Reagents and Their Condensation Products with Pyridoxal on Pyridoxal Kinase of Mouse Brain

\begin{tabular}{lcc}
\hline \multirow{2}{*}{ Inhibitors $^{a}$} & \multicolumn{2}{c}{ Inhibition ratio (\%) } \\
\cline { 2 - 3 } & (1) PAL & (2) TXP \\
\hline PAL-thiosemicarbazone & 7.5 & 0 \\
Thiosemicarbazide & 0 & 0 \\
PAL-oxime & 12.0 & 0 \\
Hydroxylamine & 0 & 0 \\
PAL-phenylhydrazone & 31.0 & 18.5 \\
Phenylhydrazone & 10 & 9.5 \\
PAL-isonicotinoylhydrazone & 66.3 & 33.5 \\
Isoniazide & 10 & 3.0 \\
PAL-azine & 67.6 & 51.6 \\
Hydrazine & 10 & 5.0 \\
PAL-semicarbazone & 36.5 & 28.0 \\
Semicarbazide & 11.0 & 3.0 \\
\hline
\end{tabular}

$a$ The final concentration of inhibitors was $2 \times 10 \mathrm{M}$.

Incubation mixture in (1) contained $0.15 \mathrm{~m} M$ PAL and ATP, $0.05 \mathrm{~m} M \mathrm{ZnSO}_{4}, 50 \mathrm{~m} M$ $\mathrm{K}$-phosphate buffer, $\mathrm{pH} 5.52,75 \mu \mathrm{g}$ kinase and inhibitors. Total volume $2.5 \mathrm{ml}$. In (2), incubation mixture contained $0.3 \mathrm{~m} M$ TXP and ATP, $0.05 \mathrm{~m} M \mathrm{ZnSO}_{4}, 50 \mathrm{~m} M \mathrm{~K}$ phosphate buffer, $\mathrm{pH} 6.42,225 \mu \mathrm{g}$ kinase and inhibitors. Total volume, $7.5 \mathrm{ml}$. Incubation was performed at $38^{\circ}$ for 1 hour.

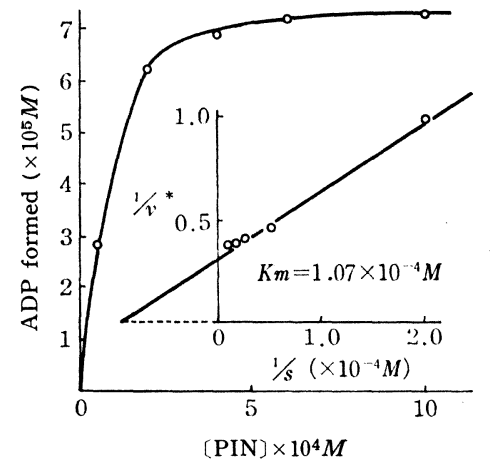

FIG. 7 Phosphorylation of Pyridoxine by the Pyridoxal Kinase of Mouse Brain

$v$, ADP formed per minute $(\mu \mathrm{g})$. Incubation mixture contained $0.4 \mathrm{mM}$ ATP, $0.05 \mathrm{mM}$ $\mathrm{ZnSO}_{4}, 50 \mathrm{~m} M$ phosphate buffer, $\mathrm{pH} 4.90,330$ $\mu \mathrm{g}$ kinase and PIN of various concentrations. Total volume $7.5 \mathrm{ml}$. Incubation was carried out at $38^{\circ}$ for 90 minutes.

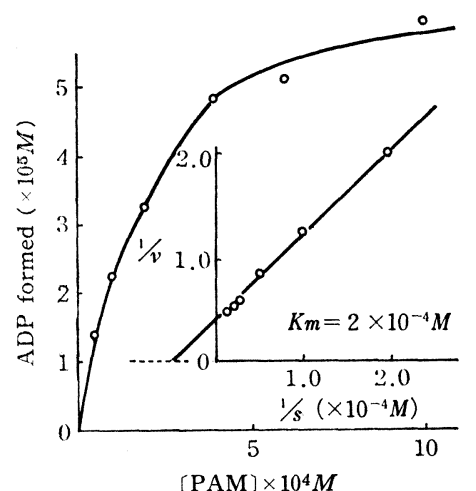

FIG. 8 Phosphorylation of Pyridoxamine by the Pyridoxal Kinase of Mouse Brain

$v$, ADP formed per minute $(\mu \mathrm{g})$. Incubation mixture contained $0.4 \mathrm{~m} M$ ATP, $0.05 \mathrm{mM}$ $\mathrm{ZnSO}_{4}, 50 \mathrm{~m} M$ phospate buffer, pH 5.52, 330 $\mu \mathrm{g}$ kinase and PAM of various concentrations. Total volume $7.5 \mathrm{ml}$. Incubation was at $38^{\circ}$ for 90 minutes.

$\mathrm{pH}$ in phosphate buffer was approximately 5.5 and 4.9 for PAM and PIN, respectively (Fig. 9).

Confirmation of PIN-P and PAM-P by PAL-kinase - As reported in the previous paper (1), the incubation mixture was poured on a column containing Dowex $1 \times 4$ (Cl-form), and the fraction eluted by $0.003 \mathrm{~N} \mathrm{HCl}$ was pooled, concentrated and developed by ascending paper chromatography together with synthetic 


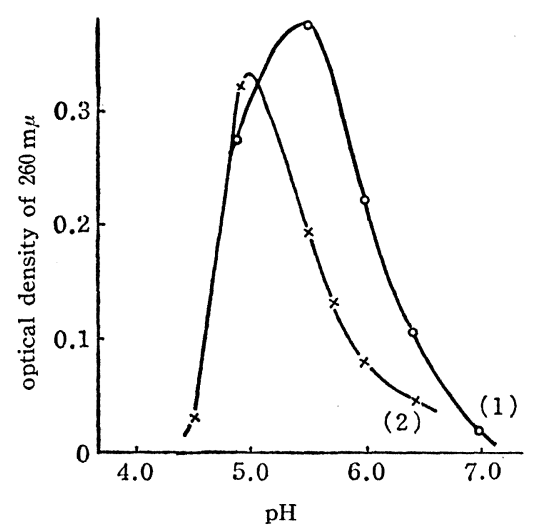

FIG. 9 pH Optima of Pyridoxal Kinase of Mouse Brain for the Phosphorylation of Pyridoxine and Pyridoxamine

Incubation mixture contained $1 \mathrm{~m} M \mathrm{PIN}$ or PAM, $0.4 \mathrm{~m} M$ ATP, $0.05 \mathrm{mM} \mathrm{ZnSO}_{4}$, $50 \mathrm{~m} M$ phosphate buffer and $330 \mu \mathrm{g}$ kinase. Total volume $7.5 \mathrm{ml}$. Incubation was carried out at $38^{\circ}$ for 1 hour. Curve (1), PAM; Curve (2), PIN.

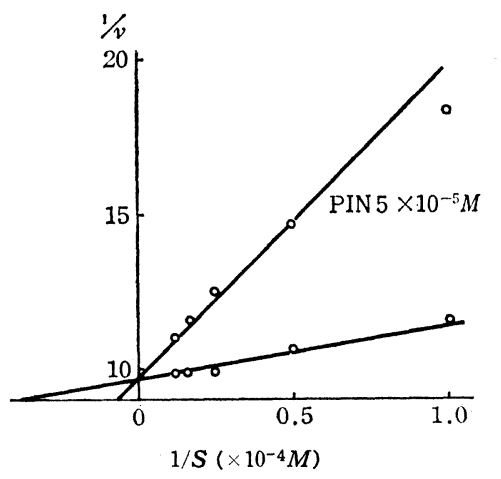

FIg. 10 Competitive Inhibition of Pyridoxine for the Phosphorylation of Pyridoxal

$v$, PAL-P formed per minute $(\mu \mathrm{g})$. Incubation mixture contained $0.4 \mathrm{mM}$ ATP, $0,05 \mathrm{~m} M$ $\mathrm{ZnSO}_{4}, 50 \mathrm{~m} M$ phosphate buffer, pH 5.52, 75 $\mu \mathrm{g}$ kinase and PAL of various concentrations. Total volume $2.5 \mathrm{ml}$. Incubation was performed at $38^{\circ}$ for 1 hour.
PIN-P and PAM-P, and the formation of PIN-P or PAM-P was confirmed by the coincidence of the $R f$ values with synthetic PIN-P or PAM-P. The developing solvents used were $(a)$ water-saturated butanol, (b) $n$-butanol-acetic acid- $\mathrm{H}_{2} \mathrm{O}(4: 1: 5)$ and $(c)$ $n$-propanol-water- $1 M$ acetate buffer, $\mathrm{pH} 5.0$ $(70: 20: 10)$. The $R f$ values were in solvent (a) PIN-P 0.054; in (b) PIN-P 0.29, PAM-P 0.17 and in $(c)$ PIN-P 0.29, PAM-P 0.19.

The competitive relation between PAL and PIN or PAM-PIN or PAM competitively inhibited the phosphorylation of PAL by PAL-kinase and under a similar condition PIN was more potent than PAM (Figs. 10, 11). In the presence of ATP $4 \times$ $10^{-4} M$ and PAL $1.5 \times 10^{-4} M$, PAM did not inhibit the kinase at $1.5 \times 10^{-4} \mathrm{M}$, inhibited $12 \%$ at $3 \times 10^{-4} \mathrm{M}$ and $31 \%$ at $1 \times 10^{-3} \mathrm{M}$. In contrast to PAM, PIN showed the inhibition of $34 \%$ at $0.5 \times 10^{-4} \mathrm{M}, 62 \%$ at $1.5 \times$ $10^{-4} \mathrm{M}$ and $95 \%$ at $1 \times 10^{-3} \mathrm{M}$. This is presumably due to the difference between the $K m$ values for PIN and PAM.

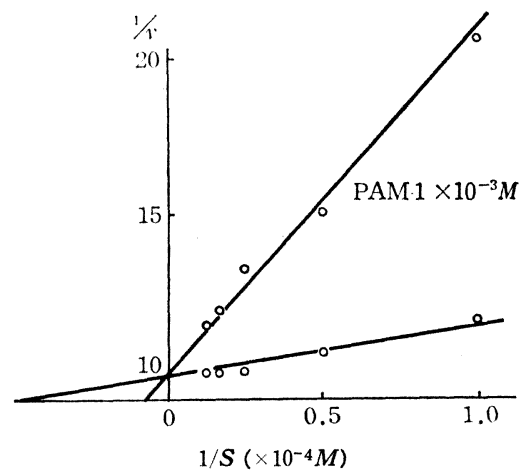

FIG. 11 Competitive Inhibition of Pyridoxamine for the Pyosphorylation of Pyridoxal

$v$, PAL-P formed per minute $(\mu \mathrm{g})$. Incubation mixture contained $0.4 \mathrm{mM}$ ATP, $0.05 \mathrm{mM}$ $\mathrm{ZnSO}_{4}, 50 \mathrm{~m} M$ phosphate buffer, pH 5.52, 75 $\mu \mathrm{g}$ kinase and PAL of various concentrations. Total volume $2.5 \mathrm{ml}$. Incubation was performed at $38^{\circ}$ for 1 hour. 
The phosphorylation of PAL and TXP derivatives - As PAL derivatives except PIN and PAM, 4-deoxy-PIN (I), 5-deoxy-PIN (II) and pyrithioxine (III), and as TXP derivatives 2-ethyl-4-amino-5-hydroxymethylpyrimidine (IV) and 2-methylmercapto-4-amino-5-hydroxymethylpyrimidine (V), were tested whether they were able to be the substrates for the PAL-kinase of mouse brain (Figs. 13, 14, 15, and 16) or not. 5-Deoxy-PIN was slightly phosphorylated (about $20 \%$ of 4 -deoxy-PIN), while pyrithioxine was not phosphorylated at all. Since these compounds seemed to be phosphorylated by the same kinase, the results concerning the substrate specificities of the kinase would be as follows: $(a)$ the PAL-kinase has the ability to act on both certain pyridine and pyrimidine derivatives, $(b)$ the methyl attached to 2-position of pyrimidine ring was able to be substituted with $\mathrm{C}_{2} \mathrm{H}_{5}$ or $\mathrm{SCH}_{3}$ group.

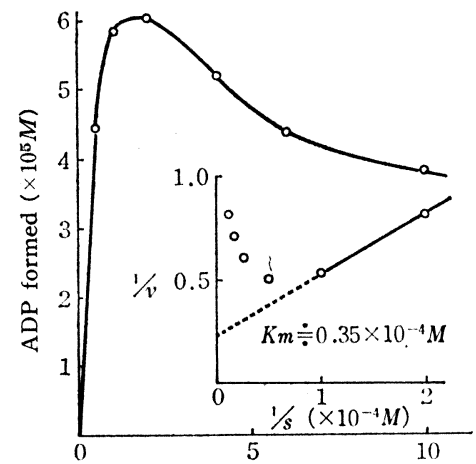

[4-Deoxy-PIN] $\times 10^{4} M$

FIG. 13 Phosphorylation of 4-Deoxypyridoxine by the Pyridoxal Kinase of Mouse Brain

The reaction condition was the same as that in Fig. 2.

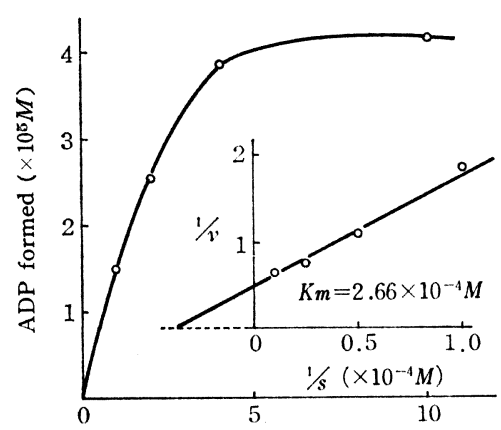

2-Ethyl-4-amino-5-hydroxymethylpyrimidine, $\times 10^{4} M$

FIG. 15 Phosphorylation of 2-Ethyl-4 amino-5-hydroxymethylpyrimidine by the Pyridoxal Kinase of Mouse Brain

The reaction condition was the same as that in Fig. 2.

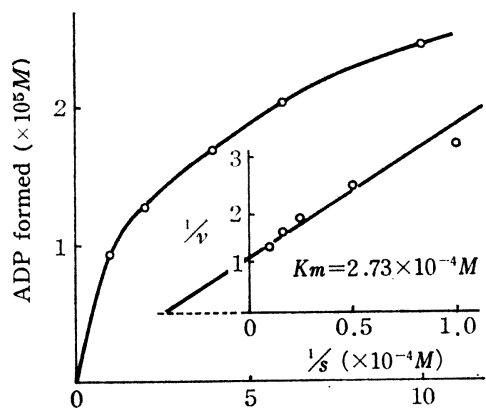

[5-Deoxy-PIN] $\times 10^{4} M$

FIG. 14 Phosphorylation of 5-Deoxypyridoxine by the Pyridoxal Kinase of Mouse Brain

The reaction condition was the same as that in Fig. 2.

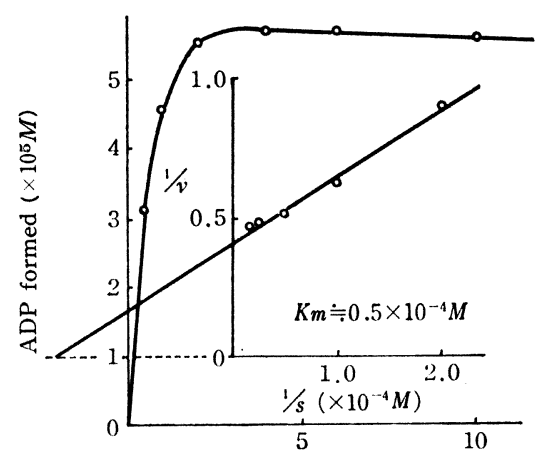

2-Methylmercapto-4-amino-5-hydroxymethyl pyrimidine, $\times 10^{4} M$

FIG. 16 Phosphorylation of 2-Methylmer. capto-4-amino-5-hydroxymethylpyrimidine by the Pyridoxal Kinase of Mouse Brain

The reaction condition was the same as that in Fig. 2. 
(c) the 4-position of the pyridine ring was able to be substituted with $\mathrm{CH}_{2} \mathrm{OH}$, $\mathrm{CH}_{2} \mathrm{NH}$ or $\mathrm{CH}_{3}$ for $\mathrm{CHO}$ group and $(d)$ the compounds without a hydroxymethyl group in the 5 position of the pyridine ring were not phosphorylated at all (such as pyrithioxine) or hardly phosphorylated (such as 5-deoxy-PIN).

Confirmation of the phosphorylation of PAL and TXP derivatives - The phosphorylation of these compounds was confirmed as follows: As described in case of identification of PIN-P and PAM-P, the incubation mixture was poured on a column containing Dowex $1 \times 4$ (Cl-form) and the fraction eluted by $0.003 \mathrm{~N} \mathrm{HCl}$ was pooled, concentrated and developed by ascending paper chromatography. The developing solvent used was the mixture consisting of $n$-propanol-water- $1 M$ acetate buffer, $\mathrm{pH} 5.0(70: 20: 10)$. The formation of 4 -deoxy-PIN-P was confirmed by the coincidence of the $R f$ value with the synthetic 4-deoxy-PIN-P. In case of 5-deoxyPIN-P, 2-ethyl-4-amino-5-hydroxymethylpyrimidine and 2-methylmercapto-4-amino-5hydroxymethylpyrimidine whose phosphorylated compounds were not provided synthetically, their unphosphorylated compounds and AMP were developed as controls. The spots different from the unphosphorylated compounds, AMP or PIN-P, were cut out, and extracted for 3 hours at $38^{\circ}$. The extract was again poured on the column containing Dowex $1 \times 4(\mathrm{Cl}$-form) and $0.003 \mathrm{~N} \mathrm{HCl}$ fraction was pooled for measurement of ultraviolet absorption spectrum. As the result, the spectra of the three compounds except 5-deoxy-PIN-P coincided well with those of the unphosphorylated compounds in acidic and basic solutions. (The phosphorylation at 5-hydroxymethylposition does not affect the spectra of the original compounds. The compound which appears to be 5-deoxy-PIN-P was not sufficient in quantity to measure the ultraviolet absorption spectrum.) Moreover, phosphorylation was confirmed with color test on the paper chromatogram. It was confirmed further by the quantitative analysis of phosphoric acid of the compounds in question that the PAL-kinase in the presence of ATP phosphorylated 4-deoxy-PIN, 2-ethyl-4-amino-5-hydroxymethyl-pyri-<smiles>Cc1ncc(CO)c(C)c1O</smiles>

(I)<smiles>Cc1cnc(C)c(O)c1CO</smiles>

(II)<smiles>Cc1ncc(CSSCc2cnc(C)c(O)c2CO)c(CO)c1O</smiles><smiles>CCCCCCc1ncc(CO)c(N)n1</smiles>

(IV)<smiles>CSc1ncc(CO)c(N)n1</smiles>

(V)
(I) 4-Deoxypyridoxine

(II) 5-Deoxypyridoxine

(III) Pyrithioxine

(IV) 2-Ethyl-4-amino-5-hydroxymethylpyrimidine

(V) 2-Methylmercapto-4-amino5-hydroxymethylpyrimidine

FIg. 12 
midine and 2-methylmercapto-4-amino-5-hydroxymethylpyrimidine to their respective monophosphate ester.

It is an interesting fact that a small amount of ADP was formed when 5-deoxyPIN, which has no hydroxymethyl group in the 5 position, was incubated with ATP and the kinase. The formation of 5-deoxy-PIN-P remains to be investigated.

Requirement of $\mathrm{Zn}^{2+}$ ion - Also for the phosphorylation of PIN, PAM, (I), (II), (IV), and (V) $\mathrm{Zn}^{2+}$ was found to be essential (Fig. 12).

\section{ACKNOWLEDGEMENT}

The authors wish to thank Prof. Y. Nose, the Kyoto Prefectural University of Medicine for his helpfull suggestions, and Mrs. Yasuko Murakami for her continued cooperation during the course of this study. This work was supported by the grant of the Vitamin B Research Committee.

\section{REFERENCES}

1. Tsubosaka, M., Vitamins, 33, 293 (1966).

2. Tiselius, A., Hjerten, S., and Levin, O., Arch. Biochem. Biophs., 65, 132 (1956).

3. Wada, H., and Snell, E. E., J. Biol. Chem., 236, 2089 (1961).

4. Siekevitz, P., and Potter, V. R., J. Biol. Cheml, 200, 187 (1953).

5. Egami, F., Nucleic Acids and Nucleoptoteins, p. 156 (Vol. I, 1926), Kyoritsu Shuppansha (Tokyo).

6. McCormick, D. B., and Snell, E. E., J. Biol. Chem., 236, 2085 (1961).

7. McCormick, D. B., Gregory, M. E., and Snell, E. E., J. Biol. Chem. 236, 2076 (1961), 